\begin{tabular}{|c|c|c|}
\hline & Int.J.Curr.Microbiol.App.Sci (2016) 5(11): 407-415 & \\
\hline & International Journal of Current Microbiology and Applied Sciences & \\
\hline & ISSN: 2319-7706 Volume 5 Number 11 (2016) pp. 407-415 & \\
\hline EXCELLENT & Journal homepage: http://www.1jcmas.com & \\
\hline PUBLISHERS & & www:jemas.com \\
\hline
\end{tabular}

Original Research Article

http://dx.doi.org/10.20546/ijcmas.2016.511.047

\title{
Relationship between Dietary Patterns and Body Mass Index of Pregnant Women in Khamis Mushayt, Saudi Arabia
}

\author{
Bothaina Abd El Hakeem ${ }^{1,2}$, Hanan A. $\operatorname{Emarah}^{3}$ and Sraa A. Abo Melha \\ ${ }^{1}$ Department of Special Food and Nutrition, Food Technology Research Institute, Agriculture \\ Research Center, Giza, Egypt \\ ${ }^{2}$ Department of Home Economic, College of Administration and Home Economic, \\ Abha, King Khalid University (KKU), KSA \\ ${ }^{3}$ Department of Nursing, College of Applied Medical Sciences, Bisha University, KSA \\ ${ }^{4}$ Department of Chemistry, Faculty of Science, King Khalid University, Abha, KSA \\ *Corresponding author
}

\section{Keywords \\ Dietary habits, pregnant women, Body Mass Index.}

\section{Article Info}

Accepted:

23 October 2016

Available Online:

10 November 2016

\section{A B S T R A C T}

Pregnant women need more essential nutrient than other women. The body of pregnant women needs 300 calories per day to support the growth of the baby. It is important to eat healthy foods every day to tissues and organs develop during weeks of your pregnancy and the baby is always growing. The purpose of this study was to identify dietary patterns of pregnant women and examine the association between these patterns and body mass index. This cross sectional descriptive study was conducted on one hundred and fifty Saudi women (150 females) between the ages of 18 and 45 . They were chosen by a systemic random method, recruited from hospital women and birth in khamismushayt, Saudi Arabia. This study was carried out to determine (BMI), dietary habits and lifestyle behaviors among pregnant women. The survey was conducted March 2015.A self-administered questionnaire was used to collect the research data. All subjects were asked to complete the Food Frequency Questionnaire (FFQ) with questions on dietary habits. A self-reported height and weight were used to calculate BMI $(\mathrm{BMI}=$ weight $(\mathrm{kg}) / \mathrm{height}(\mathrm{m}) 2)$. Statistical analyses were performed using the Statistical Package (SPSS). On the basis of self-reported height and weight. The Majority of participants $51.7 \%$ were classified over weight while 24.5 and 23.2 of participant were classified normal and obese respectively. There were significant differences between BMI category and dietary patterns. About $21.3 \%$ from all participants were normal weight who ate meat one to two times per week while $18 \%$ of participants have obese who ate meat rarely per week. About $22.5 \%$ of participants were overweight who ate chicken three to four times per week while $26.6 \%$ of participants were overweight consumed rarely fish per week and about (23.3\%) of pregnant women were obese who consumed rarely cheese during pregnancy. Vegetables and fruits consumed there was statistically significant difference $(\mathrm{p}<0.001)$ between all most of participants $(28.5 \%)$ ate fruits and vegetables one to two times per week. $31.8 \%$ from all participants ate sweets one to two times per week. All most of participants $(84.1 \%)$ reported rarely practicing physical activity while $2 \%$ reported only practice physical activity three times per week. Our results show that there were significant differences between BMI category and dietary patterns but the dietary habits of pregnant women were unhealthy and more than half of participants ate fast foods. Our study suggests that increasing nutrition education and counseling to Promote optimal fetal nutrition, which includes: ensuring appropriate maternal nutrition and micronutrient supplementation before and during pregnancy and providing counseling on diet and food safety to pregnant women. 


\section{Introduction}

World Health Organization Regional Office for Europe, 2001 reported that women have different health issues than men. In addition to obvious differences related to reproductive health, such as diseases related to pregnancy and birth, certain disorders, such as anaemia, depression, anxiety and eating disorders, are more frequent in women than in men.

Maternal health refers to the health of women during pregnancy, childbirth and the postpartum period. Perinatal health refers to health from 22 completed weeks of gestation until 7 completed days after birth. Newborn health refers to babies' first month of life. A healthy start during the perinatal period influences infancy, childhood and adulthood according to World Health Organization Regional Office for Europe, 2004.

According to document of the New Zealand Ministry of Health (2006) showed that Energy requirements increase in pregnancy by about 12 percent. This is because of the increase in maternal body weight, an average 10-15 percent increase in basal metabolic rate (BMR), the energy costs of the growing foetus, and maternal physiological changes in pregnancy.

Energy requirements are higher in later pregnancy but may be, at least partially, offset by the mobilization of fat stored in early pregnancy Energy requirements increase in pregnancy by about 12 percent. This is because of the increase in maternal body weight, an average 10-15 percent increase in basal metabolic rate (BMR), the energy costs of the growing foetus, and maternal physiological changes in pregnancy. Energy requirements are higher in later pregnancy but may be, at least partially, offset by the mobilisation of fat stored in early pregnancy.
Streitfeld, 1978 reported that pregnant women be informed of the risks and benefits of certain dietary practices. This is not a simple task, as many foods, beverages and medications carry unknown risks.

The main objectives of this study to identify dietary patterns of pregnant women and examine the association between these patterns and body mass index.

\section{Subject and Methods}

This cross sectional descriptive study was conducted on one hundred and fifty Saudi women (150 females) between the ages of 18 and 45 . They were chosen by a systemic random method, recruited from hospital women and birth in khamismushayt, Saudi Arabia. This study was carried out to determine (BMI), dietary habits and lifestyle behaviors among pregnant women, The survey was conducted March 2015. For ethical consideration all selected women were informed about the objectives and proposal of the study, Also the selected women completed questionnaire. A selfadministered questionnaire was used to collect the research data. All subjects were asked to complete the Food Frequency Questionnaire (FFQ) with questions on dietary habits. A self-reported height and weight were used to calculate BMI (BMI = weight $\quad(\mathrm{kg}) /$ height $\quad(\mathrm{m}) 2)$. Statistical analyses were performed using the Statistical Package (SPSS).

\section{Results and Discussion}

A total of 150 pregnant completed the questionnaires. Most women (84.8\%) were aged 35 or young. All most of the participants $(76.8 \%)$ did not complete degree graduate less than a quarter of the women $(22.5 \%)$ possessed a college (table $1)$. 
Table 2. represent the health history of participants all most of the participants reported did not suffer anemia, diabetes and hypertension but $34.4 \%, 22.5 \%$ and $17.2 \%$ had anemia, diabetes and hypertension respectively.

Frequency distribution of participants based on BMI categories in table (3). The Majority of participants $51.7 \%$ were classified over weight while 24.5 and 23.2 of participant were classified normal and obese respectively.

Table (4) shows relationship BMI there was a statistically significant difference $(\mathrm{p}<0.01)$ between the dietary habits and BMI. About $21.3 \%$ from all participants were normal weight who ate meat one to two times per week while $18 \%$ of participants have obese who ate meat rarely per week. About 225 of participants were overweight who ate chicken three to four times per week while $26.6 \%$ of participants were overweight consumed rarely fish per week and about $(23.3 \%)$ of pregnant women were obese who consumed rarely cheese during pregnancy. A high than of participants were normal $(19.3 \%)$ who ate eggs one to two times per week during pregnancy. Vegetables and fruits consumed there was statistically significant difference $(\mathrm{p}<0.001)$ between all most of participants $(28.5 \%)$ ate fruits and vegetables one to two times per week. $31.8 \%$ from all participants ate sweets one to two times per week.

Nearly half of sampled women $48.3 \%$ reported drinking a milk daily during their pregnancies. Most participants reported consuming vitamin during the pregnancy.

About half of participants (52.3\%) reported eating fast foods during then pregnancy. While consumption patterns for fast foods in take were varied $(70.2 \%)$ reported eating fast once per week, $20.5 \%$ reported eating fast foods two times per week and $(8.6 \%)$ only ate fast foods three times per week during then pregnancy. All most of participants $(84.1 \%)$ reported rarely practicing physical activity while $2 \%$ reported only practice physical activity three times per week.

The current data demonstrated that $(84.4 \%)$ of participants were aged 35 or young and more than two third of the participants did not get university degree. However these findings was not in agreement with Ismail Eman Mohamed et al., 2013 studied the mean age for all subjects was31.6 $\pm 7.15 \mathrm{y}$ and most subjects got university degree $(58.3 \%)$ or secondary education $(27.8 \%)$.

According to the current study findings, $34.4 \%, 22.5 \%$ and $17.2 \%$ of the participants had anemia, diabetes and hypertension respectively. Ismail Eman Mohamed et al., 2013 reported that $36.8 \%$ and $18.4 \%$ had obesity and hypertension respectively while $42.1 \%$ did not have other diseases.

The current data found that statistically significant difference $(\mathrm{p}<0.001)$ between BMI and dietary patterns. More than half $51.7 \%$ of pregnant women were overweight and $23.2 \%$ and $24.5 \%$ were obese and normal weight respectively. In China Haoyue Gao et al., 2013 mentioned that most women had a pre-pregnancy BMI within the normal range before conceiving $(68.7 \% ; 18.5 \leq \mathrm{BMI}<25)$. About a quarter were found to be underweight with a BMI of $<18.5$ (26.3\%; $20.8 \%$ in urban vs. $35.6 \%$ in rural areas); while a small number were overweight with a BMI of $\geq 25$ to $<30$ $(5.1 \%)$. None of the women had been obese $(\mathrm{BMI} \geq 30)$ before conceiving.

The current data studied that $42.4 \%$ of participants ate red meat one to two times 
per week while $33.1 \%$ ate rarely red meat per week. In general, a Western dietary pattern (characterized by high intakes of red and processed meat, refined grains, sweets, desserts and potatoes), has been shown to be associated with greater weight gain in women (Schulze et al., 2006).

According to the current study findings 36.4 $\%$ of pregnant women ate chicken three to four times per week and $31.1 \%$ ate chicken one to two times per week but $4.6 \%$ ate rarely chicken per week. Juliana et al., 2013 reported that Most of the items in the common-Brazilian pattern are typical Brazilian foods. For example, the main meals (lunch and dinner) usually contain rice or pasta and beans with beef, chicken or eggs, together with artificial juice. Chicken was the most frequently reported meat consumed $(98.5 \%)$, followed by beef $(84 \%)$, then pork (52\%). Most women (81.9\%) consumed meat at least once a week, with $30.4 \%$ consuming meat at least four times a week (Santiago et al., 2013).

In this study, $49.7 \%$ of the pregnant women ate fish rarely per week but $29.1 \%$ ate fish once per week. However these findings were not in agreement with Santiago, et al., 2013 studied that Most participants (73.9\%) consumed fish during pregnancy. The most commonly consumed type of fish was tuna (52\%), followed by tilapia (34.2\%) and salmon $(25.5 \%)$. Less than a quarter of the women (19.9\%) also reported eating other kinds of fish or shellfish, with shrimp being the most frequently written in option. Most women ate fish less than once a week $(80 \%)$, and nearly a third of women $(31.2 \%)$ ate fish during all three trimesters.

The current study results found that nearly a third of pregnant women $(31.1 \%)$ ate cheese a once per week. The Chinese government has urged an increase in milk production and consumption as an effective approach to improve the $\mathrm{Ca}$ intake of the Chinese population ( $\mathrm{Lu}, 2013$ and $\mathrm{Ge}$ and Chang, 2001). Integrating all this core information, the emphasis on improving $\mathrm{Ca}$ intake must not be restricted to dairy products, but rather should be extended to include selected $\mathrm{Ca}$ fortified soybean products such as tofu. Differences between the first time mothers and others in the pregnant group, and between those without and with children in the non-pregnant group were analyzed. Pregnant women with children were found to consume significantly less raw milk cheese, and to score significantly higher on preparing meat well-done as compared to pregnant women without children (Verbeke and Bourdeaudhuij, 2013).

In this study, $35.1 \%$ ate egg rarely per week but nearly a third of pregnant women (33.1 $\%)$ ate egg one to two times per week and nearly half of pregnant women drank milk daily. These findings were in agreement with Santiago et al., 2013 reported that Most women (95.4\%) drank milk during their pregnancies. Of those women, $79 \%$ drank low-fat milk, 20.9\% drank whole milk, 6.7\% drank organic milk, $3.9 \%$ drankskim milk, and $8.6 \%$ drank "other" milk, with $3.6 \%$ identifying "other" as soy milk. Twothirds of women $(66.6 \%)$ drank milk at least 4 times per week. Most (71.4\%) drank milk during all three trimesters.

The current datademonstrated that most women $(84.1 \%)$ did not practice physical activity during their pregnancies. Clapp, 2008 studied that Maintaining exercise during pregnancy may have many benefits including short terms benefits to the baby and long term benefits for the mother and further pregnancies. Long term effect of continuing vigorous weight-bearing exercise during pregnancy was examined in a follow up observational study in 39 subjects. 
The current data demonstrated that more than a quarter of women pregnant ate vegetables and fruits one to two times per day and $27.2 \%$ of pregnant women ate vegetables and fruits rarely. A similar finding was reported in a study described aspects of) maternal intake of food, drink and medication in populations of predominantly Hispanic Southern California by (Santiago et al., 2013). All women reported eating fresh fruit during their pregnancies. Two thirds $(65.8 \%)$ of women ate fruit at least four times a week. Although the majority of women $(77 \%)$ reported consuming fruit during all three trimesters of their pregnancies, only a third of the women $(31.1 \%)$ ate the recommended amount of more than one serving of fruit per day.

The current data demonstrated that more than quarter of pregnant women $27.8 \%$ ate sweets daily. In line with these finding were in agreement with Santiago et al., 2013 reported that almost all women (97.5\%) reported eating high-sugar desserts during their pregnancies. Ice cream was the favored dessert: $82.7 \%$ reported eating ice cream. Additionally, $70.1 \%$ reported eating baked desserts, $65 \%$ reported eating chocolate, and $3.6 \%$ reported eating other desserts, such as candy or frozen dessert beverages during their pregnancies. Most women (76.2\%) consumed desserts between one time per month and three times per week. Over half $(53.2 \%)$ reported eating sugary desserts throughout their pregnancies.

According to the current study findings, 68.9 $\%$ reported that took dietary supplementary during pregnancy in agreement with Santiago et al., 2013 reported that most women consumed prenatal vitamins during their pregnancies $(83.4 \%)$.

In this study, most women $(84.8 \%)$ reported eating fast foods during their pregnancies and $70.2 \%$ ate fast foods once per week. these s was agreement with Santiago et al., 2013 reported that nearly all of the +women (96 \%) ate fast foods during their pregnancies with burgers -/being the most commonly consumed item (85.2\%), followed by french fries $(77.9 \%)$, chicken products (53.6\%), and other fast foods such as Mexican fast foods and chicken salads.

Table.1. Distribution of participants in different age groups.

\begin{tabular}{|ll|c|c|c|c|}
\hline & & Frequency & Percent & Valid Percent & Cumulative Percent \\
\hline Age & $15-20$ & 16 & 10.6 & 10.7 & 10.7 \\
& $20-25$ & 35 & 23.2 & 23.3 & 34.0 \\
& $25-30$ & 51 & 33.8 & 34.0 & 68.0 \\
& $30-35$ & 26 & 17.2 & 17.3 & 85.3 \\
& $35-40$ & 17 & 11.3 & 11.3 & 96.7 \\
& $40-45$ & 5 & 3.3 & 3.3 & 100.0 \\
& Total & 150 & 99.3 & 100.0 & \\
Missing & System & 1 & .7 & & \\
Total & 151 & 100.0 & & \\
\hline
\end{tabular}


Table (3). Percent distribution of levels of BMI

\begin{tabular}{|ll|c|c|c|c|}
\hline & & Frequency & Percent & Valid Percent & Cumulative Percent \\
\hline Valid & Normal & 37 & 24.5 & 24.7 & 24.7 \\
& over weight & 78 & 51.7 & 52.0 & 76.7 \\
& Obese & 35 & 23.2 & 23.3 & 100.0 \\
& Total & 150 & 99.3 & 100.0 & \\
Missing & System & 1 & .7 & & \\
Total & 151 & 100.0 & & \\
\hline
\end{tabular}

Table.4 Dietary Pattern and selected behaviors of participants

\begin{tabular}{|c|c|c|}
\hline Variable & No. & $\%$ \\
\hline \multicolumn{3}{|c|}{ How many times you eat red meat per week } \\
\hline Two to three times & 64 & 42.25 \\
\hline Three to four times & 18 & 11.9 \\
\hline Daily & 15 & 9.9 \\
\hline Two times per day & 3 & 2 \\
\hline Rarely & 50 & 33.1 \\
\hline \multicolumn{3}{|c|}{ How many times you eat chicken per week } \\
\hline Two to three times & 47 & 31.1 \\
\hline Three to four times & 55 & 36.4 \\
\hline Daily & 31 & 20.5 \\
\hline Two times per day & 10 & 6.6 \\
\hline Rarely & 7 & 4.6 \\
\hline \multicolumn{3}{|c|}{ How many times you eat fish per week? } \\
\hline Two to three times & 44 & 29.1 \\
\hline Three to four times & 14 & 9.3 \\
\hline Daily & 11 & 7.3 \\
\hline Two times per day & 6 & 4 \\
\hline Rarely & 75 & 49.7 \\
\hline \multicolumn{3}{|c|}{ How many times you eat fruits and vegetables per week? } \\
\hline Two to three times & 44 & 29.1 \\
\hline Three to four times & 14 & 9.3 \\
\hline Daily & 11 & 7.3 \\
\hline Two times per day & 6 & 4 \\
\hline Rarely & 75 & 49.7 \\
\hline \multicolumn{3}{|c|}{ How many cups you drink milk daily? } \\
\hline Once & 73 & 48.3 \\
\hline Two to three times & 30 & 19.9 \\
\hline Three to four times & 20 & 13.2 \\
\hline More than four times & 12 & 7.9 \\
\hline Rarely & 15 & 9.9 \\
\hline \multicolumn{3}{|c|}{ How many times you eat sweets per week? } \\
\hline Once & 42 & 27.8 \\
\hline Two to three times & 48 & 31.8 \\
\hline Three to four times & 23 & 15.2 \\
\hline More than four times & 15 & 9.9 \\
\hline Rarely & 22 & 14.6 \\
\hline Having Fast foods & & \\
\hline
\end{tabular}




\begin{tabular}{|lll|}
\hline Yes & 79 & 52.3 \\
No & 22 & 14.6 \\
Sometimes & 49 & 32.5 \\
Frequency of fast foods per week & & \\
Three times & 13 & 8.6 \\
Twice & 31 & 20.5 \\
Once or less & 106 & 70.2 \\
How many times you practice sports per week? & \multicolumn{2}{|}{} \\
Once & 12 & 7.9 \\
Twice & 8 & 5.3 \\
Three times & 3 & 2 \\
Rarely & 127 & 84.1 \\
\hline
\end{tabular}

Consumption patterns for fast food intake were varied: $19.1 \%$ reported only eating fast foods 1-3 times during their entire pregnancies, $47.5 \%$ reported eating fast foods 1-3 times per month, and $25.7 \%$ reported eating fast foods 1-3 times per week. Only $5.5 \%$ of women reported eating fast food more than four times per week during their pregnancies. Forty-three percent of women reported eating fast foods during all three trimester.

In conclusion, our results show that there was significant differences between BMI category and dietary patterns but the dietary habits of pregnant women were unhealthy and more than half of participants ate fast foods.

\section{Recommendation}

Our study suggests that increasing nutrition education and counseling to Promote optimal fetal nutrition, which includes: ensuring appropriate maternal nutrition and micronutrient supplementation before and during pregnancy and providing counseling on diet and food safety to pregnant women.

\section{References}

Becker, W., Alexander, J., Andersen, S., Aro, A., Fogelholm, M., Lyhne, N., Meltzer, H.M., Pedersen, A.N., Pedersen, J.I. and Thorsdottir, I. 2006.
Nordic nutrition recommendations. Ugeskr Laeger, 168: 76-77.

Berg, M.J., Van, D., Chenard, C., Niebyl, J.R., Hirankarn, S., Bendich, A., Stumbo, P. 2001. Folate, zinc, and vitamin B-12 intake during pregnancy and postpartum. J. Am. Diet. Assoc., 101: 242-245.

Birth and the Family J., 5(1): 7-19.

Borrud, L.G., Krebs-Smith, S.M., Friedman, L., Guenther, P.M. 1993. Food and nutrientintakes of pregnant and lactating women in the United States. J. Nutr. Educ., 4: 176-185.

Citation: Ministry of Health. 2006. Food and Nutrition Guidelines for Healthy Pregnant and Breastfeeding Women: A background paper. Wellington: Ministry of Health. http://www.health.govt.nz/.

Clapp, J.F. 2008. Long-term outcome after exercising throughout pregnancy: fitness and cardiovascular risk. Am. J. Obstet. Gynecol., 199: 489 e 1-6.

Erkkola, M., Karppinen, M., Jarvinen, A., Knip, M. \& Virtanen, S.M. 1998. Folate, vitamin $\mathrm{D}$, and iron intakes are low among pregnant Finnish women. Eur. J. Clin. Nutr., 52: 742-748.

Ervin, R.B., Wright, J.D., KennedyStephenson, J. 1999. Use of dietary supplements in theUnited States, 1988-94. Vital Health Stat., 11: 1-14.

Ge, K.Y., Chang, S.Y. 2001. Dietary intake of some essential micronutrients in 
China. Biomed. Environ. Sci., 14: 318-324.

Hasunen, K., Kalavainen, M., Keinonen, H., Lagström, H., Lyytikäinen, A., Nurttila, A., Peltola, T., Talvia, S. 2004. The Child, Family and Food Nutrition recommendations forinfants and young children as well as pregnant and breastfeeding mothers (in Finnish). Publications of Ministry of Social Affairs and Health. Helsinki, Edita Prima.

Haugen, M., Brantsaeter, A.L., Alexander, J. \& Meltzer, H.M. 2008. Dietary supplementscontribute substantially to the total nutrient intake in pregnant Norwegian women. Ann. Nutr. Metab., 52: 272-280.

Helakorpi, S., Patja, K., Prättälä, R., Uutela, A. 2007. Health behavior and health among theFinnish adult population, spring 2006. Helsinki, National Public Health Institute.

Juliana Feliciati Hoffmann, et al. 2013. Dietary patterns during pregnancy and the association with sociodemographic characteristics among women attending general practices in southern Brazil: the ECCAGe Study. Cad.SaúdePública, Rio de Janeiro, 29(5): 970-980.

Kaartinen, P., Ovaskainen, M.L., Pietinen, P. 1997. The use of dietary supplements among Finnish adults. Scand J. Nutr., 41: 13-17.

Lu, E. Radical Shifts in China's Milk Market. Available online: http://china.org.cn/business/ news/2009-01/14/ content_ 17105973. htm (accessed on 23 July 2013).

Lyytikäinen, A., Lamberg-Allardt, C., Kannas, L. \& Cheng, S. 2005. Food consumption andnutrient intakes with a special focus on milk product consumption in early pubertalgirls in Central Finland. Public Health Nutr.,
8: 284-289.

Mathews, F., Yudkin, P., Smith, R.F. \& Neil, A. 2000. Nutrient intakes during pregnancy: theinfluence of smoking status and age. J. Epidemiol. Community Health, 54: 17-23.

Murphy, S.P., White, K.K., Park, S.Y. \& Sharma, S. 2007. Multivitaminmultimineral supplements' effect on total nutrient intake. Am. J. Clin. Nutr., 85: S280-S284.

National Nutrition Council. 2005. Finnish Nutrition Recommendations - Diet and physical activity in balance (in Finnish). Helsinki, Edita Publishing.

Ortega, R.M., Gaspar, M.J., Moreiras, O. 1994. Dietary assessment of a pregnant Spanish women group. Int. J. Vitam. Nutr. Res., 64: 130-134.

Paturi, M., Tapanainen, H., Reinivuo, H., Pietinen, P. 2008. The national FINDIET 2007survey. Publications of the National Public HealthInstitute, B23/2008. Helsinki, Helsinki University Press.

Rogers, I. \& Emmett, P. 1998. Diet during pregnancy in a population of pregnant women in South West England. ALSPAC Study Team. Avon Longitudinal Study of Pregnancy and Childhood. Eur. J. Clin. Nutr., 52: 246-250.

Sarah, E., Santiago, Grace, H., Park and Kelly, J. Huffman. 2013. Consumption habits of pregnant women and implications for developmental biology: a survey of predominantly Hispanic women in California. Nutrition $\quad J ., \quad 12: \quad 91$ .http://www.nutritionj.com/content/12/ $1 / 91$

Schulze, M.B., Fung, T.T., Manson, J.E., Willett, W.C. \& Hu, F.B. 2006. Dietary patterns and changes in body weight in women. Obesity, 14: 14441453. 
Strategic action for the health of women in Europe.Copenhagen, World Health Organization Regional Office for Europe, 2001.

Streitfeld, P.P. Congenital-Malformation teratogenic foods and additives.

Suitor, C.W. \& Gardner, J.D. 1990. Supplement use among a culturally diverse group of lowincomepregnant women. J. Am. Diet Assoc., 90: 268271.

Timbo, B., Altekruse, S., Hyman, F., Klontz, K. \&Tollefson, L. 1994. Vitamin and mineralsupplementation during pregnancy. Mil. Med., 159: 654-658.

Verbeke, W. \& De Bourdeaudhuij, I. 2007.
Dietary behaviour of pregnant versus non pregnant women. Appetite, 48: $78-86$.

Verbeke, W., I. De Bourdeaudhuij. 2007. Dietary behaviour of pregnant versus non-pregnant women / Appetite 48, $78-86$.

WHO. 2003. Regional Office for Europe.Maternal and newborn health.http://www.euro.who.int/en/hea lth-topics/Life-stages/maternal-andnewborn-health.

Yu, S.M., Kogan, M.D. \& Huang, Z.J. 2003. Vitamin-mineral supplement use among US women, J. Am. Med. Womens Assoc., 58: 157-164.

\section{How to cite this article:}

Bothaina Abd El Hakeem, Hanan A. Emarah and Sraa A. Abo Melha. 2016. Relationship between Dietary Patterns and Body Mass Index of Pregnant Women in Khamis Mushayt, Saudi Arabia. Int.J.Curr.Microbiol.App.Sci. 5(11): 407-415.

doi: http://dx.doi.org/10.20546/ijcmas.2016.511.046 